\title{
Understanding cancer networks better to implement them more effectively: a mixed methods multi-case study
}

Dominique Tremblay ${ }^{1,2^{*}}$, Nassera Touati ${ }^{3}$, Danièle Roberge ${ }^{1,2}$, Mylaine Breton ${ }^{1,2}$, Geneviève Roch ${ }^{4,5}$, Jean-Louis Denis ${ }^{3}$, Bernard Candas ${ }^{6}$ and Danièle Francoeur ${ }^{7}$

\begin{abstract}
Background: Managed cancer networks are widely promoted in national cancer control programs as an organizational form that enables integrated care as well as enhanced patient outcomes. While national programs are set by policy-makers, the detailed implementation of networks is delegated at the service delivery and institutional levels. It is likely that the capacity to ensure more integrated cancer services requires multi-level governance processes responsive to the strengths and limitations of the contexts and capable of supporting network-based working. Based on an empirical case, this study aims to analyze the implementation of a mandated cancer network, focusing on governance and health services integration as core concepts in the study.

Methods/design: This nested multi-case study uses mixed methods to explore the implementation of a mandated cancer network in Quebec, a province of Canada. The case is the National Cancer Network (NCN) subdivided into three micro-cases, each defined by the geographic territory of a health and social services region. For each region, two local health services centers (LHSCs) are selected based on their differences with respect to determining characteristics. Qualitative data will be collected from various sources using three strategies: review of documents, focus groups, and semi-directed interviews with stakeholders. The qualitative data will be supplemented with a survey that will measure the degree of integration as a proxy for implementation of the NCN. A score will be constructed, and then triangulated with the qualitative data, which will have been subjected to content analysis. Qualitative, quantitative, and mixed methods data will be interpreted within and across cases in order to identify governance patterns similarities and differences and degree of integration in contexts.

Discussion: This study is designed to inform decision-making to develop more effective network implementation strategies by thoroughly describing multi-level governance processes of a sample of settings that provide cancer services. Although the study focuses on the implementation of a cancer network in Quebec, the rich descriptions of multiple nested cases will generate data with a degree of generalizability for health-care systems in developed countries.
\end{abstract}

Keywords: Cancer, Case study, Governance, Health-care integration, Implementation, Mixed methods, Network

\footnotetext{
* Correspondence: dominique.tremblay2@usherbrooke.ca

${ }^{1}$ Centre de recherche - Hôpital Charles-Le Moyne, Centre intégré de santé et

de services sociaux de la Montérégie-Centre, 150 Place Charles-Le Moyne,

J4K OA8 Longueuil, Quebec, Canada

${ }^{2}$ Campus de Longueuil - Université de Sherbrooke, 150 Place Charles-Le

Moyne, J4K OA8 Longueuil, Quebec, Canada

Full list of author information is available at the end of the article
} 


\section{Background}

Since the mid-1990s, networks are widely promoted as an organizational form that enables integrated care as well as enhanced patient outcomes. In broad terms, networks refer to a group of three or more organizations consciously formed, organized, and directed in ways to achieve a common goal $[1,2]$. Cancer services delivery is a good example of network-based working when viewed from the perspective of service users receiving care from multiple health-care teams located in different settings $[3,4]$. The seminal Calman-Hine report was the first policy document across health care to posit that cancer services should be networked, hierarchized, and integrated to allow formalizing collaboration between health-care providers and coordination across settings [5]. Since then, most national cancer control programs in developed countries take aim at solving complex problems related to care coordination (e.g., USA [6], UK [7], France [8], Australia [9], Canadian provinces $[10,11])$. There has been a sustained push to reconfigure cancer services to conform to the network organizational form [12], which is becoming the rule rather than the exception [13]. However, implementing networks is a complex solution to complex fragmentation problems considering the number of actors with competing priorities, the multiple levels of governance (national, regional, local), the multiple care processes over a long period, and the various issues of the disease [14]. Nevertheless, according to Ferlie and colleagues, networks should continue to play an important role in cancer services modernization [3].

\section{Cancer networks as an organizational form}

Being oriented toward the achievement of specific objectives, networks in the health-care sector are intended to resolve complex coordination problems involving many actors at different levels of decision-making $[15,16]$. As such, a network is a form of collective action. It refers to a group of actors (clinicians, managers, governing bodies, patients) with their own goals, values, needs, representational schemes, and models of action who are often in competition and must be rallied around a common goal. By virtue of the illness and its treatments, persons with cancer receive care and services, either concurrently or at different points in time, from many different professionals and practitioners working in a variety of settings: medical clinics, hospitals, community health centers, and palliative care facilities among others. Providing coherent and continuous care requires moving from a logic based on autonomy and independency to one that is based on interdependency and the exchange of knowledge and expertise [17].

Some authors [18] have developed network typologies based on the characteristics of the links between partners (individuals or organizations). In the health-care sector, these links are described along a continuum ranging from tenuous links, such as those characterizing networks of exchange and information (e.g., communities of practice), to the more solid and durable links established by contracts among partners that characterize mandated networks (e.g., Kaiser Permanente in the USA). Between these two poles are networks characterized by links of collaboration among professionals and across organizations. The willingness to collaborate and the capacity to adapt are two necessary conditions for developing these links, which are forged over time around a shared clinical project, professional norms, and administrative requirements [19]. The experience of the United Kingdom's cancer network has shown how a government authority that focuses on organizational restructuring and performance rather than on knowledge sharing can have an undesirable impact on the implementation and development of cancer networks [20]. While in some cases, ministry-imposed implementation of a network can be adapted so that it becomes meaningful for the professionals involved in direct service provision, in other cases, this prescriptive approach may be perceived as an intrusive control constraining professional and organizational autonomy. These observations support the idea that even mandated networks, which are the most formalized, also rely on informal and non-hierarchical links. In other words, while the form a network might take will correspond to the links that define it, it also depends on the willingness of the actors involved to collaborate with each other. Therefore, it is important to study not only the structural and organizational determinants of network implementation but also the clinical and human determinants. In this respect, current typologies are useful but could be further refined.

As for outcomes, some studies have shown the implementation of networks to be an effective method for improving health system functioning [12]. However, the conclusions vary depending on the type of network and the clientele served. Based on a review of the network integration literature, Curry and Ham [21] concluded that ministry-imposed networks were not very effective levers for improving quality of care. There is evidence demonstrating the benefits of networks, both for patients and for the health system [22-26], access to social support [27], and overall satisfaction [25]. However, researchers concur that networks' effectiveness is extremely context-dependent and that there is no ideal network model [28].

\section{Governance of health-care networks}

The numerous factors influencing network implementation have been well documented in the literature [12, 17]. Among them are factors related to structural characteristics 
(existence of a coordinating agency outside the network, coordination mechanisms and tools, size of network, internal stability), to functioning (management competence, knowledge sharing, development of capacities for innovation, mobilization of professionals, members' efforts to participate and their engagement), and to context (health system stability, access to human and financial resources, cohesiveness, support from the community). Some studies have concluded that professional engagement, legitimacy of leaders, and trust are major determinants of a network's performance and sustainability $[17,29,30]$. While knowledge exchange and the dissemination of innovations are presented as key components of clinical networks, these activities appear to be fostered more often through informal links than through hierarchical and formal mechanisms [18].

Governance is a multidimensional concept introduced to improve health-care quality and system effectiveness. In its simplest definition, governance refers to the coordination of collective action by a body in a position of authority [31]. "Coordination of collective action" focuses on the relationships between an organization (the National Cancer Network (NCN) in our case) and its contexts. It deals with the processes that make it possible for an organization to adapt to expectations and achieve the intended results. Provan and Kenis identified two models of network governance: shared and centralized [32]. The latter, most common in health systems, is characterized by the presence of a body that assumes the lead role because of its central position in providing services to the target clientele and its authority over the distribution of resources [32]. This body steers the strategic aspects of network implementation and development by setting up certain monitoring activities. It facilitates and coordinates the efforts of all the network partners to achieve the shared objectives.

According to Langley and colleagues [12], this lead organization can be a body within the network, such as a hospital or a health clinic, or a body outside the clinical network (e.g., a government body or regional agency). A review of the literature on the determinants of network effectiveness concluded that the existence of a coordinating body exercising external control was positively associated with networks' capacity to achieve their objectives [12]. Provan and Kenis assert that designating a central authority in a network can have more positive consequences during a network's emergent phase and that this effect tends to diminish as the network matures [32]. Others observed that the control exerted by a government body focused on structures and performance may have been incompatible with professional and clinical dynamics, resulting in the failure of a cancer network implementation [33].
For effective implementation in a complex organization such as a network in the health sector, some authors suggest a multi-level governance perspective [34, 35]. The "macro" level consists of a broad policy-making structure, most likely a provincial ministry of health. The "meso" level comprises a regional health board that deals with several local care delivery settings. A "micro" governance level deals with the local provider of cancer service to patients. A multi-level governance perspective takes into account the complexity of steering collective action in a network whose partners include clinicians and nonclinicians, who are both autonomous and interdependent. Multi-level governance draws attention to the policy issues as well as the challenges relevant to local health services centers (LHSCs) management and strategic practices. At each level, governance practices focus on promoting the adaptation of cancer services provision, managing relations among partners, developing knowledge through information, formulating a vision, fostering adherence to values and norms, and providing the monitoring and control needed to ensure the intended result, that is, integration, are achieved [36].

\section{Integration of health services}

Regardless of their characteristics in governance, management, and ownership, most health-care systems face similar issues in implementing integrated networks [19]. Integration refers to both an outcome of implementing governance structures and a process that involves creating and maintaining, over time, relationships among autonomous actors that are intended to coordinate their interdependencies so they can work collaboratively to carry out a collective project ( $\mathrm{NCN}$ in our case) [21,37]. Integration can be examined in relation to its four dimensions: functional, clinical, professional, and normative [37]. Functional integration involves coherently linking together financial and information systems and network management methods. Clinical integration consists of ensuring that services provided by different professionals in different locations or organizations are connected over time and meet each person's specific needs, given the knowledge available. To achieve this, clinicians agree on working methods, use shared instruments and protocols, and participate in training and knowledge exchange activities. Professional integration is the active participation of all professionals involved in cancer care, and more particularly, of physicians in clinical teams, on committees and in network decision-making. Lastly, normative integration consists of giving actors a shared value system that will help them cooperate to achieve, effectively, the collective project in which they are involved. Normative integration also allows governance to adapt to the requirements of collaboration in the network and makes professionals and organizations aware of their interdependence in providing 
coordinated care and services. The relative importance of each of these dimensions may vary depending on the level of governance considered. For example, macro governance at the policy level will have more influence on normative and functional integration, whereas micro-level governance will act on professional and clinical dimensions of integration. The degree of integration is determined by the extent to which providers achieve these dimensions.

\section{Study aim and research questions}

This multi-case study aims to conduct a systematic indepth study of a NCN implementation, with governance and services integration as the core concepts of the analysis. To achieve this objective, our analysis will answer the following questions:

1. What are the most critical contextual factors facilitating or impeding a cancer network implementation?

2. How the governance processes that support the cancer network implementation are operationalized at the health system multiple levels?

3. How are the outcomes-integration dimensions-perceived by care providers, as well as by service users (patients/families)?

4. How and why the governance processes are associated with cancer services integration?

\section{Implementation analysis framework}

Figure 1 illustrates the implementation analysis framework for the study. In a summary exercise undertaken for pragmatic purposes, the proposed study is informed by a framework taking account three dimensions: issues in the implementation of a mandated network for patients with cancer, multi-level governance, and dimensions of health services integration. This framework connects the classic trilogy used to understand health systems [38], consisting of the following: (1) contexts-characterized by the specific features of each health system level that may influence the implantation of a NCN [12,17]; (2) processes-focused on the governance practices (vision and mission shaping, resources distribution, relationship management, knowledge management, monitoring, and control) $[34,36]$ by a lead organization that is agile enough to adapt as the network's implementation evolves; and (3) outcomes-in which the dimensions of integration (normative, functional, clinical, professional) [37] are a proxy for the cancer network implementation. This framework will guide the NCN implementation analysis in order to answer the four study questions.

\section{Empirical settings}

The cancer network in Quebec (Canada) provides the empirical setting for the study. In 1998, the province of Quebec launched its national cancer control program (Programme Québécois de Lutte Contre le Cancer) [39].

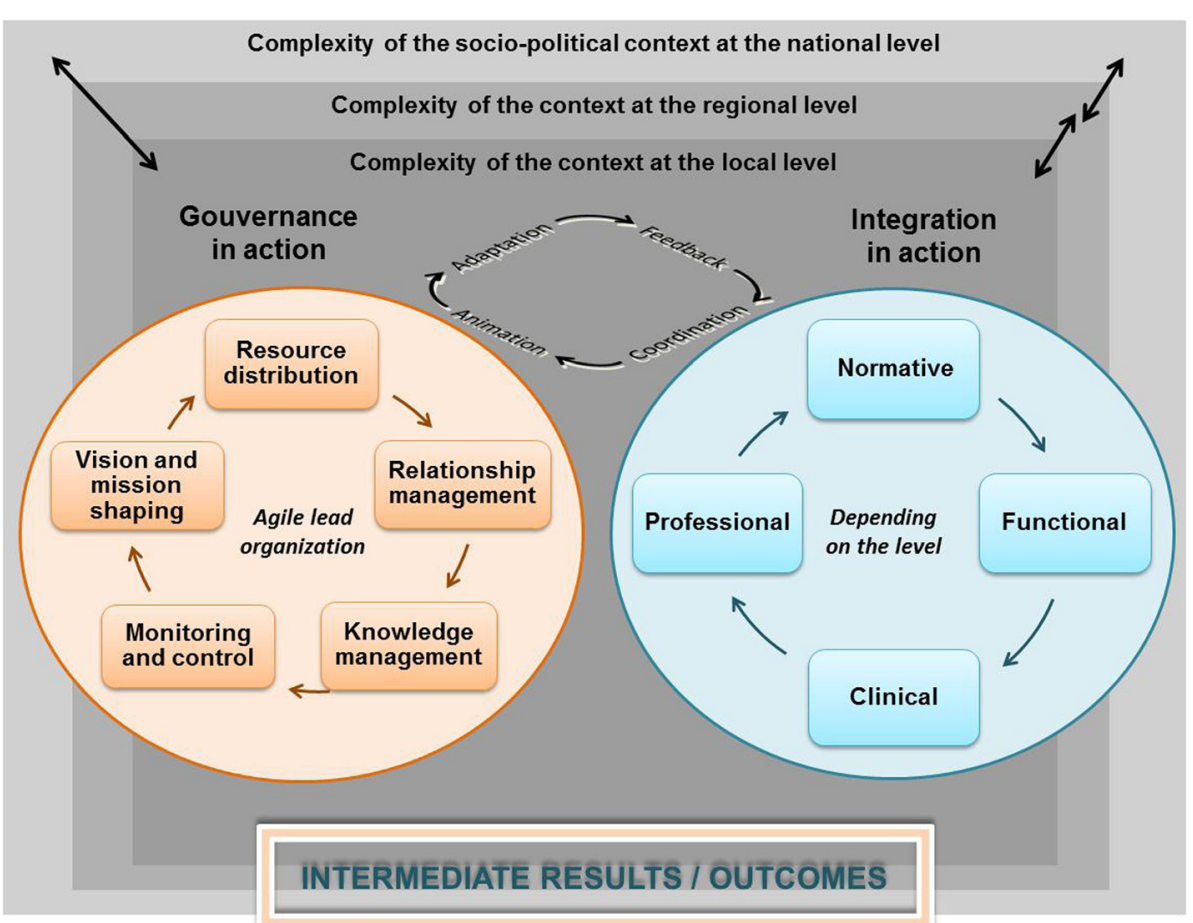

Fig. 1 Cancer network implementation analysis framework 
Its main components included setting up ministry-level governance with a structure dedicated to cancer care, creating a hierarchical cancer system, integrating networkbased services, promoting patient-centered interdisciplinary teamwork, and creating a nurse coordinator function, called the oncology pivot nurse [39]. The regional health authorities were responsible to operationalize the program components in the LHSCs on their geographic territories. In 2013, the policy-makers decided to further assess to what extent the network-based working produces the intended integration outcomes, namely to transcend organizational and professional boundaries and to reinforce the linkages between health-care teams, professionals, managers, and regions. The phenomenon of interest of this study, i.e., the implementation of a cancer network, is clearly prominent in this natural experiment. It represents a typical case that allows gaining explanations on how a network takes forms in the context of multi-level governance systems and to what extent intended integration results are achieved.

\section{Methods/design Design overview}

The preferred design for analyzing complex interventions in natural settings such as network implementation is a nested multi-case study [40]. This design is especially appropriate to analyze the dynamics of interactions among actors in a given context [41]. In comparing cases with different characteristics, multi-case studies increase the explanatory power of the analysis of organizational processes and of the meaning actors attribute to their practices. "Nested" multi-case studies, also called casewithin-case studies, examine a phenomenon of interest by subdividing it into a series of smaller cases [40]. Comparing differences and similarities in these microcases can shed light on variations in the phenomenon related to the different contexts in which it manifests. The proposed study also uses a sequential mixed methods approach (qualitative (dominate method) (QUAL) $\rightarrow$ quantitative (subordinate method) (quan)) in which the collection and analysis beginning with qualitative data is complemented by quantitative data [42]. Qualitative and quantitative data pertaining to the same questions serves triangulation purpose.

\section{Case selection}

The case is a national cancer network which offers a unique opportunity to study the implementation of network-based organizational form in the "wild." The case is subdivided into three micro-cases, each defined by the geographic territory of a health and social services region. We selected micro-cases that made up organizations in rural and urban locations, with and without specialized cancer services (e.g., academic large hospital, integrated cancer center designation), with and without the full range of cancer services (e.g., radiotherapy, ultra-specialized cancer treatments), and the time elapse since the implementation of the cancer network (Table 1). One of the micro-cases offers the potential for a longitudinal perspective on the implementation of a cancer network, given our previous studies over nearly a decade [43-46].

For each micro-case, two LHSCs will be selected based on their differences in terms of certain determining characteristics: scope of the LHSC's cancer mandate (local or regional); degree of specialization (communitybased/general, specialized, or ultra-specialized); and cancer clientele habits of cancer services utilization. The six LHSCs will be selected in partnership with the decisionmakers having intimate knowledge of these organizations. The formal partnership structure of the study is presented in Additional file 1.

\section{Qualitative data collection}

The qualitative data will be generated from four sources using different methods. We will begin by reviewing pertinent documents (e.g., minutes of meetings, action plans, regional and governmental reports). Homogeneous focus groups (FGs) will be conducted with three groups of actors from each micro-case: regional-level decision-makers, service users, care providers, and front-line managers from each LHSC. Each group will consist of 8-10 participants [47] selected through a purposive snowball sampling [48]. The FGs with care providers will explore the governance processes, the role of governance in achieving outcomes for each dimension of integration, and the processes of coordination and adaptation to network-based working. The FGs with service users will focus on describing integration

Table 1 Characteristics of the three regions (micro-cases) participating in the study

\begin{tabular}{|c|c|c|c|c|c|c|}
\hline Micro-case & $\begin{array}{l}\text { Geographic } \\
\text { location }\end{array}$ & Surface $\left(\mathrm{km}^{2}\right)$ & Population $(N)$ & $\operatorname{LHSCS}(N)$ & $\begin{array}{l}\text { Cancer network } \\
\text { implementation (year) }\end{array}$ & Cancer services offered (brief description) \\
\hline 1 & Outlying area & 15,071 & 408,188 & 5 & 2013 & $\begin{array}{l}\text { No supra regional team } \\
\text { Radiotherapy outside the region }\end{array}$ \\
\hline 2 & Metropolitan area & 498 & $1,981,672$ & 12 & 2014 & Full range \\
\hline 3 & $\begin{array}{l}\text { Rural/semi-urban/ } \\
\text { urban area }\end{array}$ & 11,111 & $1,470,252$ & 11 & 2001 & $\begin{array}{l}\text { Breast cancer supra regional team } \\
\text { Radiotherapy introduced in } 2013\end{array}$ \\
\hline
\end{tabular}


based on patients' and families' perceptions of their care experiences.

Semi-directed interviews will be conducted with key informants to explore more deeply and validate the various aspects raised in the FGs. Representatives of various government authorities and agencies will be recruited through a purposeful sampling approach [48]. Based on our previous studies, we estimate that around 30 interviews will be required per region and another dozen at the provincial level in various ministries, such that a total of about 100 interviews will be conducted. This number will be adjusted depending of the type and depth of information collected and in accordance with the principle of data saturation [49]. We will use systematic data collection grids for FGs and interviews, based on the concepts in the conceptual framework developed for the study. The grids will be adjusted to suit the type of information being sought and the persons providing the information.

\section{Qualitative data analysis}

Qualitative data from document review, focus groups, and semi-structured interviews will be analyzed in QDA Miner using a thematic coding system developed from our conceptual framework [50]. First, each case will be analyzed separately. Then, a cross-case analysis will be done to compare differences and similarities and to identify patterns in the governance processes, the extent of integration, and the results revealed by the analyses.

\section{Quantitative data collection}

The quantitative data will be collected through a survey of stakeholders (clinicians, executive directors, managers). A list of potential respondents will be developed with the partners of the study. Given the number of people involved in providing services to persons with cancer, we estimate there will be around 100 participants per LHSC. Participants will be invited to respond to an electronic questionnaire using the LimeSurvey platform. Based on our previous studies, we expect a response rate of $60 \%$ using systematic reminders at 2 and 4 weeks by email [51].

The level of integration will be measured using an instrument developed by Denis and colleagues [52, 53] in a study on the creation of health and social services centers (HSSCs) and the development of integrated health services networks. This instrument was inspired by the questionnaire originally developed by Shortell and colleagues $[54,55]$ for the Health System Integration Study and later adapted by Dobrow and colleagues [56] to evaluate the dimensions of cancer network integration in the province of Ontario (Canada). The instrument consists of 64 questions evaluated on a five-point Likerttype scale ordered to reflect progression in the degree of implementation of the four dimensions of integration. Participants are asked to respond to the questions based on their perceptions of the activities at different levels (e.g., To what extent are the managers of your local network involved in the quality management activities for cancer services? To what extent are the managers of your regional network involved in the quality management activities for cancer services?) The questionnaires are tailored for different types of respondents (clinicians, executive directors, managers) and include sociodemographic characteristics (e.g., age, sex, work setting, function).

To reinforce its validity, the questionnaire contains two vignettes presenting complex care trajectories requiring reciprocal coordination among professionals and among organizations. For the proposed study, we will adapt a vignette used in a previous study by our team to evaluate the implementation of a regional cancer network $[45,57]$. The vignette illustrates the trajectory of a patient with colon cancer from diagnosis through active treatment and into the palliative phase.

\section{Quantitative data analysis}

The data collected through the questionnaires will be analyzed using descriptive statistics. We will construct a score for level of integration by grouping individual responses and based on an index of the agreement on this question among respondents of the same LHSC. Scores for each dimension of integration will be constructed in five stages following the detailed procedure developed by James, Demaree, and Wolf [58]. In the end, these scores will range from 0 to 10 , with scores of 5 and under considered weak, 6 average, 7 good, 8 excellent, and 9 or above exceptional. Two members of our team (JLD and $\mathrm{MB}$ ) have already carried out this exercise of constructing an integration score in the study on HSSCs. The quantitative analysis results will be integrated with those of the qualitative analysis. The final step will consist of comparing the micro-cases and performing a cross-case analysis to document the degree of cancer network implementation.

\section{Study validity}

The quality and validity of the study will be key concerns throughout the research process. To address these, we will use the framework and criteria of Mays and colleagues [58], which include the following: appropriate use of a variety of methodological approaches, data triangulation, triangulation of the views of researchers and potential users, use of an analytic framework to guide data collection and analysis, collaborative sampling of cases and selection of participants, and systematic approach to data collection and analysis [59]. These approaches will strengthen the study's internal validity (trustworthiness of explanatory significance). External validity (capacity to 
generalize results) will be ensured by including different micro-cases and by analyzing how multi-level governance and their particular contexts influence the implementation of their network. This will allow us to identify the conditions required to generalize the results with other LHSNs and regional networks [60] and to maximize potential applicability and transferability of findings to cancer networks in other developed countries.

\section{Knowledge transfer plan}

The proposed study focuses on utilization, in that the resulting knowledge should align with the decision-making challenges of the potential users of the study's results [61]. Consequently, throughout the study, we will use an integrated knowledge transfer (IKT) approach, in which information will be shared throughout the implementation analysis process to foster interactions among actors at different levels of decision-making, in order to improve communication and reinforce learning [62]. An IKT is the result of a collaborative process and promotes knowledge application at all stages. The framework proposed by Baumbusch and colleagues allows us to conceive IKT as a bidirectional relationship between researchers and knowledge users, in which each participates in the coconstruction of knowledge though a collaborative approach [63]. That framework proposes two core concepts: content (the knowledge in itself) and process (application of the knowledge). Within this framework, our project involved consolidating the questions arising from the concerns expressed by policy-makers, and our aim is to create and share the emerging results in real time through research activities geared toward questions expressed by the potential knowledge users. In this way, new knowledge will be constructed that responds to their needs. The research results can thus be applied at the opportune moment, that is, when decisions need to be taken-whether at the local, regional, or provincial level-to optimize the integration required to operationalize the cancer network. Within a formal partnership structure (see Additional file 1), knowledge users at different levels of decision-making in the health system will be involved in interpreting results and in formulating concrete avenues of intervention to support decisions aimed at optimizing the integration of practices and cancer services.

\section{Study status}

The approval of the Research Ethics Board of the Research Center of the Charles-Le Moyne Hospital (HCLM) was obtained for all study procedures in participating local health services centers (record number: MP-HCLM-14010). Recruitment and data collection for this study began in July 2014 and will continue for the next year.

\section{Discussion}

The expected benefits of the research project are numerous and specific depending on the time frame of the study. First, the case study will produce new data on the achievement of the integration outcomes envisioned in the national cancer control program regarding the $\mathrm{NCN}$ implementation, as well as on the unintended or undesirable outcomes of the implementation of networkbased working. Second, it will be possible to better understand how the multi-level governance contributes to cancer services integration and how the contexts influenced this relationship. Third, the in-depth analysis of transformations in practices introduced by the NCN will help explain the gaps between the intended results and the results as they occurred in natural settings. Fourth, the strategies taken to ensure the validity of the study will help generate data and knowledge to guide decisionmaking and to deal more effectively with the challenges of implementing the cancer network.

\section{Additional file}

Additional file 1: Partnership structure of the study. Partnership structure for integrated knowledge transfer. (DOCX 61 kb)

\section{Abbreviations \\ FG: focus group; HSSC: health and social services center; IKT: integrated knowledge transfer; LHSC: local health services center; NCN: National Cancer Network; QUAL: qualitative (dominate method); quan: quantitative (subordinate method).}

\section{Competing interests}

The authors declare that they have no competing interests.

\section{Authors' contributions}

DT, NT, and DR contributed to the conception and design of the study and wrote the draft manuscript. BC, DF, and GR contributed to the knowledge transfer section and reviewed drafts of the manuscript. MB contributed to the description of integrated networks and J-LD provided expertise in governance and integrated networks and in measurement tools; they also reviewed the drafts of the manuscript. All authors read and approved the final manuscript.

\section{Acknowledgements \\ This study is supported by a grant from the Fonds de recherche du Québec - Santé (grant number 30616). We would like to acknowledge clinical team members and decision-makers for their help and advice with our research project. We would like to thank the employees of Dr. Tremblay's research program for their participation in editing the manuscript.}

\section{Author details}

${ }^{1}$ Centre de recherche - Hôpital Charles-Le Moyne, Centre intégré de santé et de services sociaux de la Montérégie-Centre, 150 Place Charles-Le Moyne, J4K OA8 Longueuil, Quebec, Canada. ${ }^{2}$ Campus de Longueuil - Université de Sherbrooke, 150 Place Charles-Le Moyne, J4K 0A8 Longueuil, Quebec, Canada. ${ }^{3}$ École nationale d'administration publique, 4750 Henri-Julien Avenue, 5th Floor, H2T 3E5 Montreal, Quebec, Canada. ${ }^{4}$ Faculty of Nursing, Université Laval, Pavillon Ferdinand-Vandry, 1050 Avenue de la Médecine, G1V OA6 Quebec, Quebec, Canada. ${ }^{5}$ Centre de recherche du CHU de Québec - Université Laval, 11 Côte du Palais, Quebec G1R 216 Quebec, Canada. ${ }^{6}$ Institut national d'excellence en santé et en services sociaux, 2535, boulevard Laurier, 5e étage, Quebec G1V 4M3 Quebec, Canada. ${ }^{7}$ Institut national de santé publique du Québec, 190 Crémazie Blvd. East, 2nd Floor, H2P 1E2 Montreal, Quebec, Canada. 


\section{Received: 20 November 2015 Accepted: 12 March 2016} Published online: 21 March 2016

\section{References}

1. Provan KG, Beagles JE, Leischow SJ. Network formation, governance, and evolution in public health: the North American Quitline Consortium case. Health Care Manage Rev. 2011;36(4):315.

2. Provan KG, Fish A, Sydow J. Interorganizational networks at the network level: a review of the empirical literature on whole networks. J Manage. 2007;33(3):479-516.

3. Ferlie E. Making wicked problems governable? The case of managed networks in health care. Oxford, UK: Oxford University Press; 2013.

4. Taplin SH, Clauser S, Rodgers AB, Breslau E, Rayson D. Interfaces across the cancer continuum offer opportunities to improve the process of care. J Natl Cancer Inst Monogr. 2010;2010(40):104-10.

5. Calman K, Hine D. A policy framework for commissioning cancer services: a report by the Expert Advisory Group on Cancer to the Chief Medical Officers of England and Wales. London: Department of health; 1995. January 20, 2016

6. Commission on Cancer. Cancer program standards: ensuring patientcentered care. Chicago, IL: 2016.

7. Department of Health. The NHS cancer plan: a plan for investment, a plan for reform. London: National Health Service; 2000.

8. Meyrieux B. INCa: projet d'établissement et orientations stratégiques 2012-2015. Bulletin Infirmier du Cancer. 2012;12(4):100-3.

9. Department of Health WA. Model of care for cancer. Perth: WA: Cancer \& Palliative Care Network; 2008. January 20, 2016.

10. Evans J, Matheson G, Buchman S, MacKinnon M, Meertens E, Ross J, et al. Integrating cancer care beyond the hospital and across the cancer pathway: a patient-centred approach. Healthc Q. 2015;17:28.

11. Vandenberg T, Coakley N, Nayler J, DeGrasse C, Green E, Mackay JA, et al. A framework for the organization and delivery of systemic treatment. Curr Oncol. 2009:16(1):4-15.

12. Turrini A, Cristofoli D, Frosini F, Nasi G. Networking literature about determinants of network effectiveness. Public Adm. 2010;88(2):528-50.

13. Sheaff R, Benson L, Farbus L, Schofield J, Mannion R, Reeves D. Network resilience in the face of health system reform. Soc Sci Medicine. 2010;70(5):779-86

14. Popp J, MacKean G, Casebeer A, Milward H, Lindstrom R. Interorganizational networks - a review of the literature to inform practice. Washington DC: IBM Center for the Business of Government; 2013.

15. Provan KG, Milward HB. Health services delivery networks: what do we know and where should we be headed? Healthc Pap. 2006;7(2):32-6.

16. Provan KG, Nakama L, Veazie MA, Teufel-shone NI, Huddleston C. Building community capacity around chronic disease services through a collaborative interorganizational network. Health Educ Behav. 2003:30(6):646-62.

17. Haines M, Brown B, Craig J, D'Este C, Elliott E, Klineberg E, et al. Determinants of successful clinical networks: the conceptual framework and study protocol. Implement Sci. 2012;7:16.

18. Ferlie E, Fitzgerald L, McGivern G, Dopson S, Exworthy M. Networks in health care: a comparative study of their management, impact and performance. In: National Institute for Health Research Service Delivery and Organisation Programme. London: Queen's Printer and Controller of HMSO; 2010. http://www.nets.nihr.ac.uk/_data/assets/pdf_file/0003/64515/FR-081518-102.pdf. Accessed 17 March 2016.

19. Wistow G, Dickinson H, Evans JM, Ross BG. Shared mental models of integrated care: aligning multiple stakeholder perspectives. J Health Organ Manag. 2012;26(6):713-36.

20. Addicott R, McGivern G, Ferlie E. The distortion of a managerial technique? The case of clinical networks in UK health care. Brit J Manage. 2007;18(1):93-105.

21. Curry N, Ham C. Clinical and service integration - the route to improved outcomes. The King's Fund. 2010. https://www.kingsfund.org.uk/sites/files/ kf/Clinical-and-service-integration-Natasha-Curry-Chris-Ham-22-November2010.pdf. Accessed: 17 March 2016

22. Hébert R, PRISMA Group, Raîche M, Gueye NR, Dubuc N, Tousignant M. Impact of PRISMA, a coordination-type integrated service delivery system for frail older people in Quebec (Canada): a quasi-experimental study. J Gerontol B Psychol Sci Soc Sci. 2010;65B(1):107-18.

23. MacAdam M. Frameworks of integrated care for the elderly: a systematic review. Canadian Policy Research Network. 2008. http://www.cprn.org/ documents/49813_EN.pdf. Accessed: 17 March 2016.
24. Wedding U, Kodding D, Pientka L, Steinmetz HT, Schmitz S. Physicians judgement and comprehensive geriatric assessment (CGA) select different patients as fit for chemotherapy. Crit Rev Oncol Hematol. 2007:64(1):1-9.

25. Kodner D. Whole-system approaches to health and social care partnerships for the frail elderly: an exploration of North American models and lessons. Health Soc Care Communit. 2006;14(5):384-90.

26. Bernabei R, Landi F, Zuccala G. Health care for older persons in Italy. Aging Clin Exp Res. 2002;14(4):247-51.

27. Sargent P, Pickard S, Sheaff R, Boaden R. Patient and carer perceptions of case management for long-term conditions. Health Soc Care Communit. 2007;15(6):511-9.

28. Béland F, Hollander MJ. Integrated models of care delivery for the frail elderly: international perspectives. Gac Sanit. 2011;25 Suppl 2:138-46.

29. Kaluzny AD, Warnecke RB. Managing a health care alliance: improving community cancer care. 2nd ed. Washington: Beard Books; 2000.

30. Provan $\mathrm{KG}$, Milward HB. A preliminary theory of interorganizational network effectiveness: a comparative study of four community mental health systems. Admin Sci Quart. 1995:40(1):1-33.

31. Hatchuel A. Prospective et gouvernance: quelle théorie de l'action collective? In: Heurgon E, Landrieu J, editors. Prospective pour une gouvernance démocratique. La Tour d'Aigues: Éditions de l'Aube: Colloque de Cerisy; 2000. p. 29-42

32. Provan KG, Kenis P. Modes of network governance: structure, management, and effectiveness. J Public Adm Res Theory. 2008;18(2):229-52.

33. Addicott R, Ferlie E. Understanding power relationships in health care networks. J Health Organ Manag. 2007;21(4-5):393-405.

34. Pomey MP, Denis JL, Contandriopoulos AP. Un cadre conceptuel d'analyse de la gouvernance clinique dans les établissements de santé. Pratiques et organisation de soins. 2008;39(3):183-94.

35. Forest P-G, Gagnon D, Abelson J, Turgeon J, Lamarche P. Issues in the governance of integrated health systems. Executive summary. 1999. http://www.cfhi-fcass.ca/Migrated/PDF/ResearchReports/Commissioned Research/pses-governihs e.pdf. Accessed 17 March 2016.

36. Denis J-L, Champagne F, Pomey MP, Préval J, Tré G. Toward a framework for the analysis of governance in health care organizations and systems. Preliminary report presented to the Canadian Council on Health Services Accreditation. Montréal: Université de Montréal; 2005.

37. Contandriopoulos AP, Denis $J$, Touati N, Rodriguez C. The integration of health care: dimensions and implementation. Groupe de recherche interdisciplinaire en santé (GRIS), Faculté de médecine, Université de Montréal. 2003. http://www.santecom.qc.ca/BibliothequeVirtuelle/GRIS/N0401.pdf. Accessed: 17 March 2016

38. Donabedian A. The quality of care. How can it be assessed? JAMA. 1988; 260(12):1743-8

39. Comité consultatif sur le cancer. Programme québécois de lutte contre le cancer. Pour lutter efficacement contre le cancer, formons équipe. Ministère de la santé et des services sociaux. Québec: Gouvernement du Québec; 1997. http://publications.msss.gouv.qc.ca/acrobat/f/documentation/1997/97729-5.pdf. Accessed 17 March 2016.

40. Stake R. Multiple case study analysis. New York: Guilford; 2005.

41. Fitzgerald L, Dopson S. Comparative case study designs: their utility and development in organizational research. In: Buchanan DA, Bryman A, editors. The SAGE handbook of organizational research methods. Thousand Oaks, CA: SAGE Publications; 2009. p. 465-83.

42. Creswell JW. Research design: qualitative, quantitative, and mixed methods approaches. 3rd ed. Thousand Oaks, CA: SAGE Publications; 2009.

43. Tremblay D, Roberge D, Cazale L, Touati N, Maunsell E, Latreille J, et al. Evaluation of the impact of interdisciplinarity in cancer care. BMC Health Serv Res. 2011;11:144.

44. Tremblay D. La traduction d'une innovation organisationnelle dans les pratiques professionnelles de réseau: l'infirmière pivot en oncologie [Ph.D. thesis]. Montréal: Université de Montréal; 2008.

45. Roberge D, Denis J-L, Cazale L, Comtois E, Pineault R, Touati N, et al Évaluation du réseau intégré de soins et de services en oncologie: l'expérience de la Montérégie. Rapport final de recherche. Ottawa: Fondation Canadienne de la recherche sur les services de santé; 2004.

46. Tremblay D, Drouin D, Lang A, Roberge D, Ritchie J, Plante A Interprofessional collaborative practice within cancer teams: translating evidence into action. A mixed methods study protocol. Implement Sci. 2010;5:53. 
47. Krueger RA, Casey MA. Focus groups: a practical guide for applied research. 4th ed. London: SAGE Publications; 2009.

48. Guest G, Namey EE, Mitchell ML. Collecting qualitative data: a field manual for applied research. Thousand Oaks: SAGE Publications; 2013.

49. Guest $\mathrm{G}$, Bunce A, Johnson L. How many interviews are enough? An experiment with data saturation and variability. Field Methods. 2006;18(1):59-82.

50. Saldana J. The coding manual for qualitative researchers. Thousand Oaks: SAGE Publications; 2009.

51. Dillman DA, Smyth JD, Christian LM. Internet, mail and mixed-mode surveys: the tailored design method. 3rd ed. Hoboken, NJ: John Wiley Co:; 2009.

52. Fitzgerald L, Ferlie E, McGivern G, Buchanan D. Distributed leadership patterns and service improvement: evidence and argument from English healthcare. Leadersh Q. 2013;24(1):227-39.

53. Denis JL, Haggerty J, Champagne F, Breton M, Gerbier M, Trabut I et al. Organization as policy instrument: The case of mandated networks in health care system. Gothenburg. 2011. http://www.egosnet.org/jart/prj3/egos/main. jart?content-id=1332406463051\&rel=de\&reserve-mode=active\&fts=Organization tas+policy+instrument. Accessed October 22015.

54. Shortell SM, Gillies RR, Anderson DA. Remaking health care in America. The evolution of organized delivery system. Second ed. New York: Jossey-Bass; 2000.

55. Shortell SM, Gillies RG, Anderson DA, Mitchell JB, Morgan KL. Creating organized delivery systems: the barriers and facilitators. Hosp Health Serv Admin. 1993;38(4):447-66.

56. Dobrow MJ, Paszat L, Golden B, Brown AD, Holowaty E, Orchard MC, et al. Measuring integration of cancer services to support performance improvement: the CSI survey. Healthc Policy. 2009:5(1):35-53.

57. Cazale L, Tremblay D, Roberge D, Touati N. La vignette: une stratégie novatrice pour apprécier la qualité des soins d'équipes interdisciplinaires en oncologie. Rev Epidemiol Sante Publique. 2006;54(5):407-20.

58. James $L R$, Demaree $R G$, Wolf $G$. Estimating within-group interrater reliability with and without response bias. J Appl Psychol. 1984;69(1):85-98.

59. Mays N, Pope C. Qualitative research in health care: assessing quality in qualitative research. BMJ. 2000;320:50-2.

60. Yin RK. Validity and generalization in future case study evaluations. Evaluation. 2013;19(3):321-32.

61. Patton MQ, LaBossière F. L'évaluation axée sur l'utilisation. In: Ridde $V$, Dagenais C, editors. Approches et pratiques en évaluation de programme. Montréal: Les Presses de l'Université de Montréal; 2009.

62. Denis J-L, Lehoux P, Tré G. L'utilisation des connaissances produites. In: Ridde V, Dagenais C, editors. Approches et pratiques en évaluation de programme. Montréal: Les Presses de l'Université de Montréal; 2009.

63. Baumbusch JL, Kirkham SR, Khan KKB, McDonald H, Semeniuk P, Tan E, et al. Pursuing common agendas: a collaborative model for knowledge translation between research and practice in clinical settings. Res Nurs Health. 2008;31(2):130-40.

\section{Submit your next manuscript to BioMed Central and we will help you at every step:}

- We accept pre-submission inquiries

- Our selector tool helps you to find the most relevant journal

- We provide round the clock customer support

- Convenient online submission

- Thorough peer review

- Inclusion in PubMed and all major indexing services

- Maximum visibility for your research

Submit your manuscript at www.biomedcentral.com/submit

C Biomed Central 